\title{
Discussão de controvérsias sociocientíficas em sala de aula: 0 ensino da biossegurança em foco
}

\section{Socio-scientific controversies discussion in classroom: the biosafety teaching in focus}

\author{
${ }^{1}$ Marco Antonio F. da Costa costa@fiocruz.br \\ ${ }^{2}$ Fernanda Veneu \\ ${ }^{3}$ Maria de Fátima Barrozo da Costa
}

\section{RESUMO}

Este ensaio parte do princípio que a discussão de temas controversos em sala de aula é relevante na educação em ciências, devido à possibilidade de criar nos alunos, uma imagem mais real e humana da atividade científica. Isto se aplica integralmente as duas vertentes da biossegurança, ou seja, aquela relacionada a engenharia genética, e aquela praticada em ambientes da saúde. Ambas possuem diversos aspectos polêmicos, que, em um processo de ensino, devem ser devidamente abordadas. Portanto, o objetivo deste ensaio é trazer contribuições para a discussão de controvérsias sociocientíficas relacionadas à biossegurança nas aulas de ciências, visando a uma formação cidadã e compatível com as novas exigências do mundo atual, e dessa forma, favorecer a tomada de decisão crítica e devidamente argumentada por parte dos alunos.

Palavras-chave: Ensino de ciências. Polêmicas científicas. Educação científica.

\begin{abstract}
This paper assumes that the discussion of controversial issues in the classroom is relevant in science education because of the possibility to create in students a more realistic image over the human scientific activity. This fully applies to the two aspects of biosafety, that is, those related to genetic engineering, and that practiced in health environments. Both have many controversial aspects which, in a teaching process must be properly addressed. Therefore, this paper aims to raise some contributions for discussions in Science classrooms, over socio-scientific controversies related to biosafety. By making school background more compatible with the new demands on society, it is possible to develop students citizenship and enrich its conditions, encouraging decision making in a critical basis.
\end{abstract}

Keywords: Science teaching. Scientific polemics. Scientific education.

1 Doutor em Ciências, professor da Escola Politécnica de Saúde Joaquim Venâncio (FIOCRUZ) e do Programa de Pós-Graduação em Ensino em Biociências e Saúde/IOC - FIOCRUZ, Rio de Janeiro.

2 Doutora em Ciências, pós-doutoranda do Programa de Pós-Graduação em Ensino em Biociências e Saúde/IOC - FIOCRUZ, Rio de Janeiro.

3 Doutora em Saúde Pública, pesquisadora da Escola Nacional de Saúde Pública Sérgio Arouca (ENSP), Rio de Janeiro. 


\title{
1 INTRODUÇÃO
}

Freire (2011, p.25) diz que "ensinar não é transferir conhecimento, porém, criar a possibilidade para a sua produção ou sua construção”. Uma das principais dificuldades dos sistemas de ensino neste contexto de mudanças tecnológicas diz respeito à complexidade do ensino. Meis (2002, p.11), discorrendo sobre o desenvolvimento da ciência nos dois últimos séculos, afirma:

\begin{abstract}
As prioridades atribuídas às tecnologias modernas conflitam de forma contínua com valores humanos previamente estabelecidos, gerando o conflito humano-tecnológico. Uma das causas desse conflito reside na forma ultrapassada de ensinar nas escolas e universidades [...] ainda não aprendemos como ajustar o novo conhecimento ao modo de ensinar.
\end{abstract}

Esta citação nos remete para Reis (2004), quando diz que controvérsias sociocientíficas têm como característica a geração de dúvidas, tanto na comunidade científica, como na sociedade. Como exemplos, temos: eutanásia, aborto, clonagem, sexualidade, impactos ambientais, sociais e culturais causados pelas novas tecnologias, como os cultivos transgênicos, as nanotecnologias, as incursões da biotecnologia nas fronteiras das nanotecnologias (CRUZADO, 2011), entre outros.

O ensino de temas como esses é afetado por diversos fatores, principalmente, pelas intencionalidades curriculares, ideologias e características religiosas das instituições educativas e dos professores. As salas de aula devem ser espaços de criatividade e reflexão e jamais de reprodução.

No mundo atual em que vivemos, rodeados pela ciência e pela tecnologia, não faltam situações a ser pedagogicamente exploradas (COSTA, 2005). Ramos e Silva (2007) e Reis (2004) consideram que a dificuldade de abordagem de temas polêmicos com dimensões sociais, científicas e tecnológicas, por professores de ciências, ainda é visível. Reis (2007, p.128) salienta que:

Existem controvérsias em todas as áreas do pensamento humano - na ciência, na história, na arte, na economia, na política, na teologia. No entanto, a forma como cada uma destas áreas de pensamento é representada no currículo acadêmico nem sempre traduz os seus conteúdos ou a sua natureza controversa.

Forgiarini e Auler (2009) afirmam que tais temas são pouco abordados nos currículos de cursos de licenciaturas. Watanabe et al. (2012) acentuam a necessidade de se discutir, no contexto escolar, estes tópicos (no artigo, essas autoras trabalham com temas ambientais), até porque a escola é o espaço estratégico e privilegiado para essas ações (COSTA e COSTA, 2013). Veneu-Lumb (2009) recomenda a inclusão de temas polêmicos nos livros didáticos como uma das formas de fomentar os debates em sala de aula.

Portanto, o objetivo deste ensaio é trazer contribuições para a discussão de controvérsias sociocientificas relacionadas à biossegurança nas aulas de ciências, contribuindo, dessa forma, para os processos de capacitação docente e do ensino de ciências, de forma geral. Não tivemos a intenção de fazer essa discussão no contexto do movimento Ciência-Tecnologia-Sociedade (CTS), embora em alguns momentos essas relações sejam evidenciadas. Tampouco houve o propósito de se discutir tecnicamente as polêmicas identificadas.

\section{O ENSINO DE TEMAS POLÊMICOS}

O referencial balizador deste ensaio está pautado, principalmente, nos trabalhos de Reis (1997; 1999; 2001; 2004; 2006; 2007; 2009; 2013; 2014), Reis e Galvão (2005; 2008), e Reis et al. (2011), autores reconhecidos nessa temática, no campo do Ensino de Ciências. 
Esses autores sustentam que os estudantes devem participar ativamente dos processos de decisão que envolvem o ensino de temas controversos. Apontam também que esses conteúdos não podem ser ministrados apenas na base técnica, e que devem levar em conta todas as possíveis imbricações contidas no seu interior, e questionam: como preparar cidadãos capazes de decidirem perante questões complexas de sua vida, se os alunos não forem estimulados a pensar criticamente sobre assuntos controversos?

Reis (2013; 2007) diz que a posição que um indivíduo assume diante de uma questão controversa depende de sua visão de mundo, de seus valores, de seus conhecimentos e de sua compreensão sobre as questões que foram construídas socialmente.

Nesse contexto, o ensino de ciências, segundo Carmo (2010, p.114):

Possui uma responsabilidade especial sobre a educação moral das pessoas, em virtude do poder que a Ciência tem de produzir destruição, desigualdade, sofrimento, ou então, progresso, harmonia e bem-estar, tudo em função dos valores e interesses daqueles que a comandam e/ou fazem.

Cabe à escola, fundamentada em tais propósitos, e acentuadamente nas disciplinas de ciências, possibilitar aos alunos a percepção dos diferentes tipos de valores, individuais ou coletivos, que perpassam pelos campos em estudo. Os estudantes devem estar preparados para entender como esses valores são gerados, bem como para atingi-los por meio de diferentes discursos, acarretando, dessa forma, a apropriação de conhecimentos com base nos quais possam tomar decisões próprias conscientes e esclarecidas. Scheidt et al. (2007, p.168) acentuam que:

O ensino de ciências na maioria das vezes se restringe unicamente aos conteúdos científicos, desenvolvendo, nos estudantes, a concepção de que a ciência é apenas um corpo organizado de conhecimentos, ignorando que por detrás dos conhecimentos existe um processo dinâmico de construção que é influenciado por vários fatores.

A educação politécnica, uma alternativa importante para o ensino de temas controversos, aponta que a formação integral é um processo contínuo, permanente e participativo, que busca desenvolver de forma harmônica e coerente com todas as dimensões do ser humano, agregando criticidade e valores. O conhecimento não deve ser fragmentado, mas sim global, oferecendo todas as vertentes que o caracterizam (SAVIANI, 2007; CACHAPUZ et al., 2004).

Não podemos nos esquecer de que tratar desses assuntos em sala de aula depende muito, também, da competência docente dos profissionais envolvidos nos processos ensino-aprendizagem de Ciências. Esses devem ter claramente a noção de que estar em sala de aula tratando de conteúdos que envolvem ciência, religião, ideologias, por exemplo, necessita, obrigatoriamente, de uma mediação aberta e abrangente, com o uso intensivo de estratégias didáticas, como: aulas interativas; trabalhos em grupos; debates, entre outras (WILLIAMS, 1994; HENDRICKS et al., 2011; VENEU-LUMB e COSTA, 2012). Sobre a participação docente nos processos de ensino de temas polêmicos, Razera e Nardi (2006, p.63) observam que:

Para tanto, os projetos pedagógicos dos cursos de licenciatura deveriam ser repensados e reestruturados com a finalidade dessa garantia, ou seja, que o futuro professor possa já na sua formação inicial discutir temas polêmicos ou controvertidos e metodologias de ensino que contemplem as possibilidades de contribuir para a formação ética e moral do estudante.

A limitação das discussões diante das relações ciência-religião-ideologia, caso da biossegurança, por exemplo, pode significar um déficit cognitivo importante nos alunos, não possibilitando debates de maior amplitude sobre as polêmicas. 
Cabe à escola promover uma educação que possibilite aos estudantes a apropriação de conhecimentos com base nos quais possam tomar decisões conscientes e esclarecidas. Em pesquisa de Pedrancini et al. (2008), os dados obtidos indicam que, no que se refere aos transgênicos, os conhecimentos ensinados na escola não têm possibilitado aos sujeitos o entendimento da realidade atual e, por conseguinte o pensar, falar e agir cientificamente.

A educação em ciências, tendo como base as considerações anteriores, envolve questões de ética e de responsabilidade social. Em função disso, o ensino, no seu desenvolvimento pedagógico entre alunos, professores, conteúdos, metodologias, entre outros, deve constantemente abordar tendências éticas nas suas relações (RAZERA e NARDI, 2006). No caso do Brasil, a Lei n. 9.394/96 (Lei de Diretrizes e Bases da Educação Nacional) coloca a ética como tema transversal e aponta que o desenvolvimento de atitudes e valores é essencial. Carmo (2010, p.114) afirma que:

A Ciência também gera continuamente demandas éticas, já que muitas questões polêmicas têm sua gênese no próprio desenvolvimento tecnológico, como é o caso dos transgênicos ou das possibilidades de manutenção estendida da vida.

\section{A BIOSSEGURANÇA COMO TEMA POLÊMICO}

A biossegurança, nosso foco pedagógico, é um campo científico que aborda questões relacionadas aos processos que envolvem organismos geneticamente modificados (OGMs) e células-tronco embrionárias (COSTA e COSTA, 2009), caracterizada como biossegurança legal. Em ambientes da saúde e laboratoriais, onde estão presentes agentes de riscos químicos, biológicos, físicos, ergonômicos e psicossociais, ela é caracterizada como biossegurança praticada (COSTA e COSTA, 2012).

Pela sua complexidade e abrangência, o ensino da biossegurança deve ser apoiado em um corpo de conhecimentos estruturado, e agregado de valores. Costa e Costa (2013, p.14) apontam que:

\footnotetext{
A Biossegurança, de forma geral, pelas suas questões controversas, que são também questões sociais, coloca em embate não apenas as comunidades científicas, como a própria sociedade. Dessa forma, a Biossegurança, enquanto atividade intencionalizada, é influenciada pelo meio e permeada de relações ideológicas e de poder, que variam de sociedade para sociedade, e que influenciam, sobremaneira, seu processo de ensino - aprendizagem.
}

A biossegurança não se sustenta apenas na base técnica, uma vez que envolve controvérsias e pressões de grupos sociais, políticos e econômicos, características que a colocam no rol dos temas polêmicos. Paese (2013, s.p.) aponta que:

Presenciamos nos últimos tempos a proliferação de extensos debates a respeito de temas que envolvem a saúde humana e o meio ambiente. Nesse contexto, diferentes atores sociais formularam agendas de atuação em torno de abordagens discordantes sobre a biossegurança, o que gerou inúmeras controvérsias a respeito do assunto.

\section{BIOSSEGURANÇA: ALGO ALÉM DAS CONTROVÉRSIAS?}

O campo da biossegurança é repleto de questões onde especialistas entram constantemente em conflitos, já que envolve defesa de valores, interesses pessoais, e de grandes grupos econômicos, e onde o marco regulatório geralmente é pautado pelos “lobbies”. Entre vários exemplos dessas controvérsias, citamos (SILVA, 2011; BERRUEZO, 2012; MASCARENHAS et al., 2012; ZANINI, 2012;CARTUJO, 2013): 
1. Os defensores da produção de OGMs afirmam que com eles será possível diminuir em grande escala a fome no mundo, em função da produtividade das safras, e pelo aumento dos nutrientes das plantas. Outros, porém, afirmam que a fome no Brasil é decorrência de políticas públicas inadequadas, de políticas econômicas e sociais em desacordo com a ética, com a equidade, com a democracia econômica;

2. Os produtores de vegetais transgênicos teriam seus lucros aumentados, mesmo sem o aumento das áreas cultivadas, não afetando dessa forma áreas de preservação ambiental;

3. A incerteza em relação aos possíveis riscos das biotecnologias - Princípio da Precaução (CORNETTE, 2004), observando que a aplicabilidade desse princípio é sempre anterior ao início da atividade que pode oferecer risco, não se esperando a configuração de qualquer dano. Outra linha aponta que o desenvolvimento da biotecnologia deve continuar e os possíveis efeitos maléficos, se houver, devem ser identificados ao longo do processo - Princípio da Pró-ação, que se baseia na necessidade de que os benefícios alcançados devem ultrapassar os possíveis efeitos gerados, resultantes do uso da nova Convergência Tecnológica, ou seja, da confluência das biotecnologias, nanotecnologias, informática e ciências cognitivas (CAVALHEIRO, 2007);

4. A produção em larga escala de insumos transgênicos resistentes a agrotóxicos leva ao aumento direto da aplicação desse produto sobre as áreas de cultivo, acarretando com isso, um acúmulo ainda maior de substâncias químicas no solo e, possivelmente, nas águas próximas às plantações;

5. No meio ambiente pairam as dúvidas sobre a possibilidade da disseminação desses organismos provocarem a extinção das espécies mais fracas, diminuindo a biodiversidade no planeta;

6. A fiscalização inadequada das lavouras com transgênicos no país;

7. A ainda tímida discussão sobre às questões éticas que perpassam às biotecnologias e ao uso de células-tronco;

8. A produção de animais transgênicos com características específicas poderia contribuir para a diminuição do uso de animais convencionais em pesquisas científicas, e dessa forma atenuar os movimentos contrários ao uso de animais de laboratórios.

Além dos exemplos anteriores, relacionados à biossegurança legal, temos os derivados da biossegurança praticada, como (MASTROENI, 2008):

1. Desconhecimento da situação atual dos acidentes em ambientes de saúde - não temos, no Brasil, uma política de notificação desses eventos;

2. O uso indiscriminado de substâncias químicas nas instituições de ensino e de pesquisa, sem o devido controle, principalmente nos aspectos de descarte, entre outros;

3. A participação ainda pequena do trabalhador nas discussões que envolvem os acidentes de trabalho;

4. A incorporação inadequada das questões de biossegurança por parte dos gestores, principalmente no setor saúde; 
5. 5) A fiscalização frágil, por parte dos órgãos públicos, sobre os processos que manipulam agentes biológicos e químicos em instituições federais, estaduais e municipais, em relação àquelas praticadas em ambientes industriais;

6. O uso indiscriminado de animais em experimentações científicas e discussões sobre o marco regulatório no Brasil.

7. As controvérsias, como as citadas, e as suas respectivas discussões são fundamentais para o desenvolvimento da ciência, em todos os campos do conhecimento. Como a ciência é feita por pessoas, e não por seres perfeitos e neutros, as marcas culturais, sociais e políticas interferem no que os cientistas fazem. As controvérsias também possuem uma temporalidade: o que é controvérsia num determinado momento histórico, deixa de ser controvérsia em outro (ASSAD, 2013).

Os problemas sociocientíficos, segundo Abd-El-Khalich (2003), são pouco delimitados, multidisciplinares, impregnados de valores e afetados pela insuficiência de conhecimentos, o que leva a avaliações positivas e negativas. Esse cenário está totalmente compatível com a biossegurança no Brasil, principalmente em relação aos processos envolvidos com OGMs.

\title{
5 CONTRIBUIÇÕES PARA O ENSINO DA BIOSSEGURANÇA
}

Dearden (1981) salienta que uma abordagem completa de qualquer disciplina passa pela referência aos seus elementos controversos, destacando a não inclusão destes elementos, no currículo de Ciências, como responsável pela veiculação de ideias distorcidas sobre a ciência, frequentemente descrita como controversa e neutra.

Forgiarini e Auler (2009, p.402), citando Reis (2004), apontam que, para esse autor:

\begin{abstract}
Questões controversas surgem pelos impactos sociais de inovações científico/tecnológicas que dividem tanto a comunidade científica, como a sociedade em geral. Desse modo, estas questões não se resumem a disputas acadêmicas internas e restritas à comunidade científica, uma vez que em relação a elas há divergências.
\end{abstract}

A abordagem das controvérsias científicas e tecnológicas da biossegurança em salas de aulas de ciências deve acontecer de forma contextualizada (PEREIRA et al. 2012), para que os alunos desenvolvam competências que os tornem cidadãos capazes de decidirem perante questões complexas de sua vida, como as demandadas por esse campo do conhecimento. Salienta-se que entendemos por contextualização o processo de tornar socialmente relevantes os conteúdos científicos do currículo.

Essa contextualização deve abordar as diversas dimensões imbricadas à biossegurança, como as questões éticas, econômicas, políticas, ideológicas, religiosas e, logicamente, técnicas. Um exemplo se debater em aula é a Lei de Biossegurança, que oferece um leque de oportunidades pedagógicas, considerando-se as complexas relações envolvidas e o seu processo de construção (BORBA e PEREIRA, 2009; COSTA e COSTA, 2009). Fala-se de transgênicos, mas não se fala da forma como a lei de biossegurança foi construída, nem tampouco dos interesses e das ideologias envolvidos.

Outro conteúdo que possibilita discussões envolve alguns conceitos estruturantes da biossegurança (PEREIRA et al., 2009), como os de perigo e risco. Questões ambientais, como resíduos sólidos e líquidos, agrotóxicos, manuseio de produtos químicos, ergonomia, procedimentos hospitalares humanos e veterinários, podem 
muito bem ser trabalhadas à luz da biossegurança, assim como vários temas que perpassam pelas dimensões anteriormente citadas.

Para que esse processo de ensino ocorra, há necessidade de que os professores de ciências estejam atualizados e comprometidos com essa prática da educação plural e interdisciplinar, e isenta de doutrinações. Além disso, os temas polêmicos devem estar presentes nos projetos políticos-pedagógicos das escolas como conteúdos obrigatórios, e não deixá-los como temas transversais e sujeitos à aplicação voluntária dos docentes. A nossa experiência docente em biossegurança aponta que a falta de interesse de muitos professores em discutir controvérsias deste campo do conhecimento, pode estar relacionada a uma possível insegurança em lidar com contradições, que muitas vezes vão contra seus próprios princípios.

O ensino da biossegurança deve ser apoiado em um corpo de conhecimentos estruturado, e agregado de valores. Esse processo educativo, que busca transformar o conhecimento cultural do professor, gerado em interações sociais diversas, em elemento pedagógico no ensino de ciências, deve sempre ser incentivado, e juntamente com a aplicação adequada dos elementos didáticos, pode favorecer, sem dúvida, um processo de ensino eficiente e eficaz.

Um elemento importante nesse sistema de ensino é a transposição didática, ou seja, o mecanismo, através do qual analisamos o movimento do saber sábio, produzido pelos cientistas, para o saber a ensinar (àquele que está nos livros didáticos) e através deste, ao saber ensinado, àquele que realmente acontece em sala de aula (VALENTE, 2003). Esse mecanismo, no caso da biossegurança, deve ser bem observado pelos docentes, haja vista, como já vimos, as imbricações desse campo do conhecimento.

Essa transposição tem a ver com a escolha dos conteúdos. Para o ensino da biossegurança, devem-se considerar: o desenvolvimento do pensamento lógico; a ampliação das interações entre o conhecimento científico e necessidades da sociedade; o desenvolvimento de estruturas conceituais mais complexas, que permitam a assimilação de futuros conhecimentos; a aplicação de estratégias cognitivas e técnicas para a solução de problemas relacionados à biossegurança. Esses conteúdos devem possibilitar ao aluno uma visão integrada e interdisciplinar dos fatores presentes na biossegurança, considerando àqueles de maior interesse dos alunos, mas que também sejam significativos para uma determinada época e realidade (COSTA e COSTA, 2012). Costa (2005) aponta, em seu estudo sobre o ensino da biossegurança em cursos da área de saúde, que praticamente não existe uma integração de conteúdos entre as disciplinas, ou seja, muitos docentes desconhecem o que outros falam, e que também não existe uma ordenação lógica de conteúdos.

Essa descontinuidade pedagógica dos conteúdos se acentua quando se lida com controvérsias sociocientíficas, já que dessa forma, os alunos não conseguem desenvolver capacidades analíticas que permitam uma tomada de decisão.

Uma técnica que pode ser utilizada pelos professores é o estudo de caso, que incentiva os alunos a analisarem criticamente o tema em debate, principalmente os aspectos relacionados aos diferentes pontos de vista. Nessa técnica, o docente adquire um papel fundamental, já que, como mediador do processo, e sem "tomar partido”, mas incentivando a participação de todos, deve direcionar a discussão para que os elementos chave do debate sejam identificados, e categorizados, para que sejam, posteriormente, sistematizados epistemologicamente, e assim, retornem aos alunos de forma sistematizada e com base conceitual adequada, possibilitando, dessa maneira, a construção de conhecimentos, e favorecendo a tomada de decisão. Dentre os possíveis conteúdos que podem ser abordados em estudos de casos, além daqueles tradicionais da biossegurança, identificamos alguns, conforme o Quadro 1: 
Quadro 1 - Exemplos de oportunidades pedagógicas para estudos de casos utilizando algumas controvérsias da biossegurança

\begin{tabular}{|l|l|}
\hline \multicolumn{1}{|c|}{ TEMA } & \multicolumn{1}{c|}{ DISCUSSÃO } \\
\hline Lei Brasileira de Biossegurança & $\begin{array}{l}\text { Processo de construção da lei, embates éticos, embates religiosos à luz } \\
\text { das diversas vertentes, embates legais, pontos críticos da lei, Protocolo de } \\
\text { Cartagena. }\end{array}$ \\
\hline Alimentos transgênicos & $\begin{array}{l}\text { Conceitos, possíveis usos, benefícios, riscos, consumo atual, países } \\
\text { produtores, áreas cultivadas, pesquisas em desenvolvimento, Princípio da } \\
\text { Precaução, Princípio da Pró-Ação, entre outros. }\end{array}$ \\
\hline Células-tronco & $\begin{array}{l}\text { Conceitos, possíveis usos, benefícios, riscos, pesquisas em desenvolvimento, } \\
\text { perspectivas da ciência. }\end{array}$ \\
\hline Animais de laboratório & $\begin{array}{l}\text { Consumo atual, benefícios para a produção de medicamentos, riscos, } \\
\text { questões éticas, animais transgênicos, modelos alternativos à experimentação } \\
\text { animal, legislação brasileira. }\end{array}$ \\
\hline Agrotóxicos & $\begin{array}{l}\text { Conceitos, consumo atual, benefícios, riscos, modelos alternativos, pesquisas } \\
\text { em desenvolvimento. }\end{array}$ \\
\hline Meio Ambiente & $\begin{array}{l}\text { Possíveis impactos dos OGMs no solo, ar e águas, exemplos concretos de } \\
\text { efeitos degenerativos ao ambiente. }\end{array}$ \\
\hline $\begin{array}{l}\text { Acidente de trabalho na área de } \\
\text { saúde }\end{array}$ & $\begin{array}{l}\text { Situação atual, sistemas de notificação de acidentes, acidentes mais usuais, } \\
\text { profissões mais afetadas, papel dos sindicatos, legislação brasileira, conceitos } \\
\text { de perigo e risco. }\end{array}$ \\
\hline Sociedade e riscos tecnológicos & $\begin{array}{l}\text { Principais riscos atuais decorrentes das novas tecnologias, como as } \\
\text { biotecnologias, nanotecnologias, e informática, novas relações sociais. }\end{array}$ \\
\hline
\end{tabular}

Fonte: Elaborado pelos autores.

Para o sucesso da aplicação da técnica de estudo de caso em biossegurança, é primordial que o professor disponibilize informações atuais sobre o tema em discussão, apresentando tanto quanto possível as suas divergências. Entre as fontes para obtenção dessas informações estão: filmes, notícias de jornais e revistas, artigos científicos, palestras com especialistas, entre outros.

Por ser a biossegurança um universo de dimensão pluralista, aberta, e multifacetada, o seu ensino deve ser contextualizado no campo interdisciplinar, principalmente porque muitos dos seus conteúdos podem ser discutidos em diversas áreas do conhecimento/disciplinas, e dessa forma, o processo educativo poderá ocorrer de modo mais eficiente e eficaz.

\section{CONSIDERAÇÕES FINAIS}

Entendemos que tratar de temas polêmicos em sala de aula favorece, sem dúvida, a maior inserção dos alunos nas questões sociais e tecnocientíficas, propiciando a eles condições de formação contextualizada dos seus pontos de vista. Para isso, torna-se importante que, no currículo do ensino de ciências, sejam colocados esses temas, para que as controvérsias sociocientíficas que, de alguma forma, impactam o cotidiano dos indivíduos, sejam discutidas. Cabe, também, aos professores incentivar essa discussão.

No caso da biossegurança, campo que ultimamente se desenvolve de forma intensa, e ao mesmo tempo, também se tornou um ator central em inúmeras “questões” - saúde, meio ambiente, ética, desenvolvimento sustentável - em todos os setores da vida cotidiana: em casa, na escola ou no local de trabalho, compreender adequadamente as suas controvérsias e os seus impactos sobre esse novo contexto de mundo é uma ação que necessita ser buscada constantemente. 
Nessa linha, o ensino da biossegurança deve ser pautado por discussões filosóficas, históricas, econômicas, sociais e técnicas pertinentes, para que tenhamos alunos "antenados” com as demandas atuais da Ciência, Tecnologia e Sociedade, e dessa forma, possam argumentar e pensar criticamente sobre esse campo do conhecimento. Forgiarini e Auler (2009, p.400) frisam que:

\begin{abstract}
No processo educacional, dentre vários problemas para os quais é preciso buscar encaminhamentos coletivos, apresenta-se o da desvinculação entre o "mundo da vida" e o "mundo da escola". "Mundo da vida" marcado por problemas, por temas polêmicos e/ou sociais, pela crise social do desemprego, pela fome, pela violência. Contexto hegemonicamente ignorado pelo "mundo da escola", o qual, na maioria das vezes, constitui-se num mundo fechado, isolado, com suas componentes disciplinares fragmentadas, representando ilhas que não dialogam entre si e nem possuem conexões com os problemas vividos pela comunidade escolar, como, por exemplo, polêmicas ligadas aos Organismos Geneticamente Modificados (OGMs) e a clonagem de seres vivos.
\end{abstract}

Portanto, defendemos que, pela sua abrangência, imbricações e possíveis impactos na sociedade, a biossegurança deve receber atenção especial em todos os níveis dos processos de ensino de ciências, do básico a pós-graduação. Além disso, entendemos que podemos colocar a biossegurança, em função das suas características, em um patamar de tema sensível, conceito que desenvolveremos em outro ensaio.

Agradecimento: Ao CNPq, pelo apoio.

\title{
REFERÊNCIAS
}

ABD-EL-KHALICH, F. Socioscientific issues in pre-college Science classrooms: The primacy of learners` epistemological orientations and views of natures of science. In: ZEIDLER, D.L. (Ed.). The role of moral reasoning in socioscientific issues and discourse in science education (pp. 41-61). Dordrecht, The Netherlands: Kluwer Academic Publishers, 2003.

ASSAD, L. Controvérsias, debates, disputas e farsas: a ciência não é feita por deuses. ComCiência - Revista Eletrônica de Jornalismo Científico, out. de 2013. Disponível em: < http://comciencia.br/comciencia/handler. php?section=8\&edicao=92\&id=1135 $>$. Acesso em janeiro de 2014.

BERRUEZO, J.A. La polémica sobre la seguridad de los organismos modificados genéticamente y los itosanitarios y el estudio Seralini. Revista Salud Ambiental, v.12, n.2, 2012, 77-81.

BORBA, C.M.; PEREIRA, M.E.C. Organismos geneticamente modificados: como trabalhar legalmente? Vol 2. Rio de Janeiro: Publit, 2009. Disponível em: $<$ http//www.fiocruz.br/ioc/cgilua.exe/sys/start.htm?sid=9 $>$.

CARTUJO, J.L. Erradicar el hambre com biotecnologia: promesas, inquietudes y desafios em um mundo globalizado. Aposta, n.59, oct-dic, 2013,1-35.

CACHAPUZ, A.; PRAIA, J.; JORGE, M. Da educação em ciências às orientações para o ensino das ciências: um repensar epistemológico. Ciência \& Educação, Bauru, v. 10, n. 3, 2004, 363-381.

CARMO, B.C.R. Padrões morais, valores e conceitos empregados por alunos de ensino fundamental em discussões sociocientíficas. Dissertação (Mestrado) - Faculdade de Educação da Universidade de São Paulo, São Paulo, 2010.

CAVALHEIRO, E.A. A nova convergência da ciência e da tecnologia. Novos Estudos - CERAP, São Paulo, n.78, jul. 2007, 23-30. 
CORNETTE, P.L. Será que o verde irá deixar a bandeira brasileira? Breve análise do Projeto de Lei 2401/2003. A saída brasileira para biossegurança e Organismos Geneticamente Modificados (OGMs). Relatório de Impacto Ambiental e participação pública. Jus Navigandi, Teresina, a. 8, n. 457, out. 2004. Disponível em: <http://www1.jus.com.br/doutrina/texto.asp?id=5620>. Acesso em 15 de janeiro de 2013.

COSTA, M.A.F. Construção do Conhecimento em Saúde: o ensino de biossegurança em cursos de nível médio na Fundação Oswaldo Cruz. 2005. Tese (Doutorado em Ensino em Biociências e Saúde), Instituto Oswaldo Cruz, Rio de Janeiro, 2005. Disponível em: https://www.arca.fiocruz.br/handle/icict/19555>. Acesso realizado em janeiro de 2016.

COSTA, M.A.F.; COSTA, M.F.B. Biossegurança em Saúde no Ensino de Ciências. Revista Práxis, n. 9, jun.de 2013, 11-15.

; __ Entendendo a biossegurança: epistemologia e competências para a área de saúde. 3. Ed.

Rio de Janeiro: Publit, 2012.

; _ـ Educação em biossegurança: contribuições pedagógicas para a formação profissional em saúde. Ciência e Saúde Coletiva, v.15, supl.1, Rio de Janeiro, 2010, 1741-1750.

. Biossegurança de OGM: uma visão integrada. Vol.1. Rio de Janeiro: Publit, 2009. Disponível em: $<$ http//www.fiocruz.br/ioc/cgilua.exe/sys/start.htm?sid=9>.

CRUZADO, G.A. La enseñanza y capacitacion em Biotecnología desde la perspectiva de la Educación General. Revista Umbral - Universidad de Puerto Rico, n.4, maio de 2011, 66-78.

DEARDEN, R. Controversial issues and the curriculum. Journal of Curriculum Studies, v.13, n.1, 1981, 3744.

FORGIARINI, M.S.; AULER, D.A. A abordagem de temas polêmicos na educação de jovens e adultos: o caso do “florestamento" no Rio Grande do Sul. Revista Electrónica de Enseñanza de las Ciencias, v.8, n.2, 2009, 399-421.

FREIRE, P. Pedagogia da Autonomia: saberes necessários a prática educativa. 43. Ed. Rio de Janeiro: Paz e Terra, 2011.

HENDRICKS, J.S.; BURKSTRAND-REID, B.; CARBONE, J. Teaching Controversial Topics. College of Law, Faculty Publications. Paper 94, 2011. Disponível em: <http://digitalcommons.unl.edu/lawfacpub/94>.

MASCARENHAS, C.F.D.; STIPP, N.A.F.; CAMPOS, R.A.; STIPP, M.E.F. Organismos geneticamente modificados: uma abordagem sob a ótica do Direito Ambiental. Geografia, Londrina, v. 21, n. 3. Set-dez 2012, 23-39.

MASTROENI, M.F. A difícil tarefa de praticar a biossegurança. Ciência e Cultura, São Paulo, v.60, n.2, 2008, 4-5.

MEIS, L. Ciência, Educação e o conflito humano-tecnológico. São Paulo: SENAC, 2002.

PAESE, J. A política da biossegurança: conexões e tensões na tecnociência. ComCiência - Revista Eletrônica de Jornalismo Científico, out. de 2013. Disponível em: < $\underline{\text { http://comciencia.br/comciencia/handler. }}$ php?section=8\&edicao=92\&id=1135>. Acesso em janeiro de 2014. 
PEDRANCINI, V.D.; NUNES, M.J.C.; GALUCH, M.T.B.; MOREIRA, A.L.O.R.; NUNES, W.M.C. Saber científico e conhecimento espontâneo: opiniões de alunos do ensino médio sobre transgênicos. Ciência \& Educação, Bauru, v. 14, n. 1, 2008, 135-146.

PEREIRA, M.E.C.; TEIXEIRA, P.; COSTA, M.A.F.; JURBERG, C.; BORBA, C.M. A importância da abordagem contextual no ensino de biossegurança. Ciência e Saúde Coletiva, v.17, n. 6, 2012, 1643-1648.

; COSTA, M.A.F.; COSTA, M.F.B.; JURBERG, C. Reflexões sobre conceitos estruturantes em biossegurança: contribuições para o ensino de ciências. Ciências \& Cognição, v. 14, n. 1, 2009, 296-303.

RAMOS, M. B.; SILVA, H. C. Para pensar as controvérsias científicas em aulas de ciências. Ciência \& Ensino, Campinas, v. 1, 2007, 1-16.

RAZERA, J.C.C.; NARDI, R. Ética no ensino de ciências: responsabilidades e compromissos com a evolução moral da criança nas discussões de assuntos controvertidos. Investigações em Ensino de Ciências, v.11, n.1, 2006, 53-66.

REIS, P. Promoting students collective socio-scientific activism: teachers' perspectives. In: BENCZE, L.; ALSOP, S. (Ed.). Activist science and technology education. Dordrecht: Springer, 2014. p. 547-574. (Cultural Studies of Science Education, v. 9).

Da discussão à ação sociopolítica sobre controvérsias sóciocientíficas: Uma questão de cidadania. Ensino de Ciências e Tecnologia em Revista, 3(1), 2013, 1-10.

. Ciência e controvérsia. Revista de Estudos Universitários, Sorocaba, v. 35, n. 2, 2009,. 9-15;

Os Temas Controversos na Educação Ambiental. Pesquisa em Educação Ambiental, v. 2, n. 1, 2007, 125-140.

. Uma iniciativa de desenvolvimento profissional para a discussão de controvérsias sociocientíficas em sala de aula. Interacções, 4, 64-107m 2006.

Controvérsias sócio-científicas: discutir ou não discutir? Tese (Doutorado) - Faculdade de Educação da Universidade de Lisboa, Lisboa, 2004.

O ensino das ciências através da discussão de controvérsias: realidade ou fiç̧ão? In: SILVA, B. D.; ALMEIDA, L. S. (Orgs.), Atas do VI Congresso Galaico-Português de Psicopedagogia (367-379). BragaPortugal: Centro de Estudos em Educação e Psicologia da Universidade do Minho, 2001.

. A Discussão de Assuntos Controversos no Ensino das Ciências. Inovação, 12, 1999, 107-112.

A promoção do pensamento através da discussão dos novos avanços na área da biotecnologia e da genética. Dissertação (Mestrado em Educação) - Departamento de Educação, Faculdade de Ciências, Universidade de Lisboa, Lisboa, 1997.

; FARIAS, C. B. M.; GALVÃO, C.; RAPOSO, A, S. M. S. F. S. Ligação escola universidade: uma experiência de colaboração promotora do desenvolvimento profissional dos professores. In GUIMARÃES, C. M.. REIS, P.. AKAKARI, A.; GOMES, A. (Orgs.), Formação e profissão docente (pp. 60-79) Araraquara, SP: Junqueira e Marin. 2011.

; GALVÃO, R. C. Controvérsias sócio científicas e práticas pedagógicas de jovens professores. Investigações em Ensino de Ciências, 10(2) 131-160, 2005. 
; GALVÃO, C. Os professores de Ciências Naturais e a discussão de controvérsias sociocientíficas: dois casos distintos. Revista Electrónica de Enseñanza de las Ciências, 7(3), 2008, 746-772.

SAVIANI, D. Trabalho e educação: fundamentos ontológicos e históricos. Revista Brasileira de Educação, v.12, n.34, jan./abr. 2007, p: 152-180.

SCHEID, N.M.J.; FERRARI, N.; DELIZOICOV, D. Concepções sobre a natureza da ciência num curso de ciências biológicas: imagens que dificultam a educação brasileira. Investigações em Ensino de Ciências, v.12, n.2, 2007,157-181.

SILVA, P.F. Educação em bioética: desafios na formação de professores. Revista Bioética, v.19, n.1, 2011, 23145.

VALENTE, W.R. Saber científico, saber escolar e suas relações: elementos para reflexão sobre a didática. Revista Diálogo Educacional, v.4, n.10, 2003, pp. 1-11.

VENEU-LUMB, F.; COSTA, M.A.F. Reflexões e discursos sobre a vida humana: novos subsídios para aulas de ciências. Ciência \& Educação, Bauru, v.18, n. 2, 2012, 403-418.

E a vida humana, o que é? O diálogo entre a ciência, a religião, os professores e o senso comum: enriquecendo o ensino de ciências. 2009. Tese (Doutorado em Ensino em Biociências e Saúde). Rio de Janeiro, Instituto Oswaldo Cruz/Fundação Oswaldo Cruz (IOC/Fiocruz), 2009. Disponível em: <http://arca.icict.fiocruz. br/handle/icict/4083>. Acesso realizado em 10 jun. 2014.

WATANABE, G.; STRIEDER, R.B.; GEHLEN, S.T. Desafios e possibilidades para a abordagem de temas ambientais em aulas de Física. Revista Brasileira de Pesquisa em Educação em Ciências, v. 12, n.1, 2012, 205-222.

WILLIAMS, J.A. Classroom in conflict: teaching controversial subjects in a diverse society. Albany: State University of New York Press, 1994. 